\title{
Bone mineral density in nonsteroid treated early rheumatoid arthritis
}

\author{
B D Shenstone, A Mahmoud, R Woodward, D Elvins, R Palmer, F Ring, A K Bhalla
}

\begin{abstract}
Objectives-To determine whether significant reduction in bone mass is detectable in early disease in patients with rheumatoid arthritis (RA) and to examine the possible influences of disease activity and physical disability on bone mineral density (BMD) of the lumbar spine (LS) and femoral neck (FN).

Methods-LS and FN BMD values were measured and $Z$ scores determined in a cross-sectional study of 104 patients with RA of less than five years duration. BMD values were also compared between a subgroup of 64 patients and a normal control group matched for age, sex, menopausal status and body mass. BMD values and $Z$ scores were correlated with disease activity, measured by the Stoke Index, disability, measured by HAQ score, and disease duration.

Results-Premenopausal female patients with RA had significantly reduced mean FN Z scores $(-0.62,95 \%$ CI -0.30 to -0.94$)$ which correlated with HAQ scores (Rs $0.358, p=0.05)$ and age (Rs 0.397, $p=0 \cdot 03)$. There were no significant changes of BMD in males or postmenopausal females. Disease duration and disease activity did not correlate with BMD changes.

Conclusion-BMD is reduced in premenopausal female patients with early $R A$ possibly related to the attainment of peak bone mass. No significant reduction of BMD was found in males or postmenopausal females with early disease. Physical disability but not disease activity appears to play a role in the reduction of FN bone mass.
\end{abstract}

Royal National

Hospital for

Rheumatic Diseases,

Upper Borough Walls,

Bath BA1 1RL,

United Kingdom

B D Shenstone

A Mahmoud

$\mathrm{R}$ Woodward

D Elvins

R Palmer

F Ring

A K Bhalla

Correspondence to:

Dr B D Shenstone

Department of

Rheumatology,

Administration 3,

RGH Concord,

Hospital Road,

Concord, NSW 2139

Australia.

Accepted for publication

24 May 1994

(Ann Rheum Dis 1994; 53: 681-684)

With the advent of precise methods of measuring bone mineral density (BMD) there is good evidence that generalised osteoporosis occurs in rheumatoid arthritis (RA). ${ }^{1-10}$ Potential aetiological factors include corticosteroid treatment, decreased physical activity with progressive disease and a direct effect of inflammatory mediators on bone turnover. $^{24-6}$ 9-11 Current controversies include whether all, or only some, patients with RA are affected and the nature and contribution of various aetiological factors. The influence of these factors is likely to be most clearly defined is highest and change most easily quantified, and there is less influence of previous treatment and functional impairment on bone turnover.

This study examines a cohort of patients with RA not treated with corticosteroids with a disease duration of less than five years to determine whether significant reduction in bone mass is detectable in early disease and to examine the possible influence of disease activity, and physical activity on the BMD of the lumbar spine (LS) and femoral neck (FN).

\section{STUDY POPULATION}

\section{(A) RA Group}

A total of 104 patients with RA (ARA criteria $1987)^{12}$ of less than five years duration were enrolled over a period of 18 months. Thirty seven males, 30 premenopausal females and 37 postmenopausal females were recruited from a general rheumatology outpatient or early synovitis clinic. Patients of unknown menopausal status or who were perimenopausal, defined as the onset of menopausal symptoms within the previous five years or a perimenopausal hormone profile on blood testing, were excluded. Other exclusion criteria were current or previous treatment with oral corticosteroids, hormone replacement therapy, thyroxine, vitamin $\mathrm{D}$, abnormal thyroid function tests previous fragility fracture and coexistant disease associated with altered bone metabolism. Patients with marked BMD scan abnormalities known to falsely elevate BMD values, including marked scoliosis, marked osteophyte formation and vertebral crush fractures, were excluded. Plain radiographs of the lumbar spine and hip were not routinely performed to exclude these changes or coexistant aortic calcification.

\section{(B) Control Group} early in the disease process, when bone mass

Sixty four of the RA patients comprising 23 males, 20 premenopausal females and 21 postmenopausal females, were matched for age (within five years), sex, menopausal status and body mass (within 10\%) with 64 normal individuals recruited from hospital staff and spouses and a retirement group. These individuals did not have any diseases nor were taking any drugs known to affect bone turnover nor did they have a history of osteoarthritis. Exclusion criteria were as for the RA group but thyroid function tests were not performed.

\section{Methods}

Each patient underwent a detailed history and examination with details of age, menopausal 
status, duration of disease, current and previous drug treatment, current and previous illnesses, weight, height, duration of early morning stiffness (EMS), joint count, Ritchie Index $^{13}$ and modified Stanford Health Assessment Questionnaire (HAQ) ${ }^{14}$ being recorded. Blood was taken for erythocyte sedimentation rate (ESR), C reactive protein (CRP), thyroid function tests and sex hormone profile including $\mathrm{LH}, \mathrm{FSH}$ and oestradiol where appropriate. Control group details included drug therapy, current and previous illnesses, height and weight.

$\mathrm{BMD}$ was measured in the $\mathrm{L} 1$ to $\mathrm{L} 4$ lumbar vertebrae (LS) and the left femoral neck (FN) region by dual $\mathrm{x}$-ray absorptiometry using an Hologic QDR 1000 machine.

ANALYSIS

Disease activity was measured by the Stoke Index ${ }^{15}$ an algorithm incorporating joint count, duration of EMS, ESR, Ritchie Index and $\mathrm{CRP}$ to give a value ranging between 1 (minimum) activity to 17 (maximum) activity. The HAQ score was used as a measure of disability and scored giving a value ranging between 0 (normal) to $3 \cdot 0$ (severe disability).

BMD results were expressed both as an absolute value in $\mathrm{gHA} / \mathrm{cm}^{2}$ as well as the $\mathrm{Z}$ score where the absolute value is compared with an age and sex matched reference population and the value expressed as a multiple of standard deviation values.

Analysis was performed by subgroups based upon sex and menopausal status. Individual $\mathrm{LS}$ and FN BMD and $\mathrm{Z}$ scores were correlated with disease duration, Stoke Index, and HAQ scores. The mean LS BMD and FN BMD value were compared with the matched control group. The parametic statistical tests applied included analysis of variance, Pearsons correlation test and the nonpaired $t$ test. The non parametic tests included Spearman's rank correlation and the Mann Whitney U test.

\section{Results}

The characteristics of the RA cohort with subgroups based on sex and menopausal status are shown in tables 1 and 2. LS and FN Z scores in normal premenopausal individuals did not differ significantly from zero [LS mean (SEM) $0.34(0.18)$, FN mean (SEM) -0.26 $(0 \cdot 16)]$. LS and FN BMD values of the RA groups did not differ significantly from age, sex and body mass matched normal individuals (table 3). Although FN scores in premenopausal females were significantly reduced (table 2), there was no significant difference between the FN Z scores compared with the matched controls. In premenopausal females with RA LS $\mathrm{Z}$ values correlated with age (Rs $0.541, \mathrm{p} 0.002$ ) and body mass index (Rs $0.399, \mathrm{p} 0.03$ ) and $\mathrm{FN} \mathrm{Z}$ values correlated with age (Rs 0.397 , p0.03), body mass index (Rs 0.390 , p0.03) and HAQ scores (Rs 0.358, p0.05). The HAQ score was an independent predictor of $\mathrm{FN} \mathrm{Z}$ score in premenopausal patients under age 35 , but not those over age 35, after correction for age and body mass. LS and $\mathrm{FN} \mathrm{Z}$ score decreases were more marked in younger premenopausal female RA patients than older patients (figure $\mathrm{A}$ and $\mathrm{B}$ ). The younger patients did not have more severe disease nor a lower body mass than the older premenopausal RA patients. There was no correlation of LS $\mathrm{Z}$ scores with disease duration, Stoke Index or HAQ scores in any of the subgroups.

\section{Discussion}

There was no significant reduction of bone mass in male and postmenopausal females with early RA compared with normal individuals in this study. There were sufficient numbers to have a $90 \%$ probability of detecting a greater than $8 \%$ decrease in BMD values in $R A$ patients compared with normal matched individuals at the $p<0.05$ level of significance, or a $\mathrm{Z}$ score decrease of greater than $0 \cdot 4$,

Table 1 Characteristics of RA Cohort

\begin{tabular}{|c|c|c|c|c|}
\hline & Male & $\begin{array}{l}\text { Premenopausal } \\
\text { female }\end{array}$ & $\begin{array}{l}\text { Postmenopausal } \\
\text { female }\end{array}$ & Total \\
\hline $\begin{array}{l}\text { Number enrolled } \\
\text { Number taking SAARDs } \\
\text { Age }^{\star} \text { (years) } \\
\text { Bodymass index }^{\star}\left(\mathrm{kg} / \mathrm{m}^{2}\right) \\
\text { Disease duration } \\
\text { HAQ score } \text { (months })^{\star \star} \\
\text { Stoke Index }\end{array}$ & $\begin{array}{l}37 \\
20 \\
58(12) \\
26(4) \\
24(9-42) \\
0 \cdot 38(0-0 \cdot 98) \\
5(1-8)\end{array}$ & $\begin{array}{l}30 \\
14 \\
36(7) \\
25(4) \\
21(9-36) \\
0 \cdot 68(0 \cdot 31-1 \cdot 19) \\
3 \cdot 5(1-5 \cdot 5)\end{array}$ & $\begin{array}{l}37 \\
13 \\
67(7) \\
25(5) \\
14 \cdot 5(3-29) \\
0 \cdot 88(0 \cdot 13-0 \cdot 98) \\
5(1-7 \cdot 8)\end{array}$ & $\begin{array}{l}104 \\
47 \\
55(16) \\
25(4) \\
24(8-36) \\
0 \cdot 63(0 \cdot 25-1 \cdot 25) \\
4 \cdot 5(1-8)\end{array}$ \\
\hline
\end{tabular}

*Mean (SD)

$\star \star$ Median (Interquartile range).

SAARDs = slow acting anti-rheumatic drugs

$\mathrm{HAQ}=$ health assessment questionnaire

Table 2 Mean BMD values and $Z$ scores for the $R A$ cohort

\begin{tabular}{|c|c|c|c|c|}
\hline & $\begin{array}{l}\text { Male } \\
\text { Mean (SEM) }\end{array}$ & $\begin{array}{l}\text { Premenopausal } \\
\text { female } \\
\text { Mean (SEM) }\end{array}$ & $\begin{array}{l}\text { Postmenopausal } \\
\text { female } \\
\text { Mean (SEM) }\end{array}$ & $\begin{array}{l}\text { Total } \\
\text { Mean (SEM) }\end{array}$ \\
\hline $\begin{array}{l}\text { Number } \\
\text { LS BMD }\left(\mathrm{gHA} / \mathrm{cm}^{2}\right) \\
\text { FN BMD }\left(\mathrm{gHA} / \mathrm{cm}^{2}\right) \\
\text { LS Z Score } \\
\text { FN Z Score }\end{array}$ & $\begin{array}{l}37 \\
1.043(0.025) \\
0.803(0.020) \\
0.10(0 \cdot 25) \\
-0.06(0.18)\end{array}$ & $\begin{array}{l}30 \\
1.029(0 \cdot 019) \\
0 \cdot 804(0 \cdot 015) \\
0 \cdot 01(0 \cdot 20) \\
-0.62^{\star}(0 \cdot 16)\end{array}$ & $\begin{array}{l}37 \\
0 \cdot 870(0.022) \\
0.683(0.020) \\
0 \cdot 39(0 \cdot 21) \\
0.08(0 \cdot 19)\end{array}$ & $\begin{array}{l}104 \\
0.975(0.015) \\
0.758(0.012) \\
0 \cdot 18(0 \cdot 13) \\
-0 \cdot 18(0 \cdot 11)\end{array}$ \\
\hline
\end{tabular}

${ }^{\star} \mathrm{p}=<0.001$ 
Table 3 Comparison of LS and FN BMD values in RA patients and controls matched for age, sex and body mass

\begin{tabular}{|c|c|c|}
\hline & $\begin{array}{l}R A \\
\text { mean }(S D)\end{array}$ & $\begin{array}{l}\text { Controls } \\
\text { mean }(S D)\end{array}$ \\
\hline $\begin{array}{l}\text { Total (64) } \\
\text { Age (years) } \\
\text { Body Mass Index }\left(\mathrm{kg} / \mathrm{m}^{2}\right) \\
\text { LS BMD }\left(\mathrm{gHA} / \mathrm{cm}^{2}\right) \\
\text { FN BMD }\left(\mathrm{gHA} / \mathrm{cm}^{2}\right)\end{array}$ & $\begin{array}{l}53(16) \\
25(3) \\
0.982(0 \cdot 141) \\
0.759(0 \cdot 015)\end{array}$ & $\begin{array}{l}54(17) \\
25(3) \\
0.999(0 \cdot 156) \\
0.783(0.015)\end{array}$ \\
\hline $\begin{array}{l}\text { Males }(23) \\
\text { AGE (years) } \\
\text { Body Mass Index }\left(\mathrm{kg} / \mathrm{m}^{2}\right) \\
\text { LS BMD }\left(\mathrm{gHA} / \mathrm{cm}^{2}\right) \\
\text { FN BMD }\left(\mathrm{gHA} / \mathrm{cm}^{2}\right)\end{array}$ & $\begin{array}{l}57(11) \\
25(3) \\
1 \cdot 024(0 \cdot 139) \\
0 \cdot 780(0 \cdot 131)\end{array}$ & $\begin{array}{l}57(11) \\
25(2) \\
1 \cdot 022(0 \cdot 163) \\
0 \cdot 798(0 \cdot 120)\end{array}$ \\
\hline $\begin{array}{l}\text { Premenopausal females (20) } \\
\text { Age (years) } \\
\text { Body Mass Index }\left(\mathrm{kg} / \mathrm{m}^{2}\right) \\
\left.\text { LS BMD (gHA } / \mathrm{cm}^{2}\right) \\
\text { FN BMD }\left(\mathrm{gHA} / \mathrm{cm}^{2}\right)\end{array}$ & $\begin{array}{l}34(8) \\
23(3) \\
1 \cdot 025(0 \cdot 106) \\
0 \cdot 809(0 \cdot 092)\end{array}$ & $\begin{array}{l}34(8) \\
23(3) \\
1 \cdot 060(0 \cdot 128) \\
0 \cdot 847(0 \cdot 110)\end{array}$ \\
\hline $\begin{array}{l}\text { Postmenopausal females (21) } \\
\text { Age (years) } \\
\text { Body Mass Index }\left(\mathrm{kg} / \mathrm{m}^{2}\right) \\
\text { LS BMD }\left(\mathrm{gHA} / \mathrm{cm}^{2}\right) \\
\text { FN BMD }\left(\mathrm{gHA} / \mathrm{cm}^{2}\right)\end{array}$ & $\begin{array}{l}68(6) \\
27(4) \\
0 \cdot 896(0 \cdot 139) \\
0 \cdot 690(0 \cdot 107)\end{array}$ & $\begin{array}{l}68(6) \\
26(3) \\
0 \cdot 920(0 \cdot 142) \\
0 \cdot 707(0 \cdot 091)\end{array}$ \\
\hline
\end{tabular}

$\mathrm{SD}=$ standard deviation

LS = lumbar spine.

$\mathrm{FN}=$ femoral neck

$\mathrm{BMD}=$ bone mineral density.
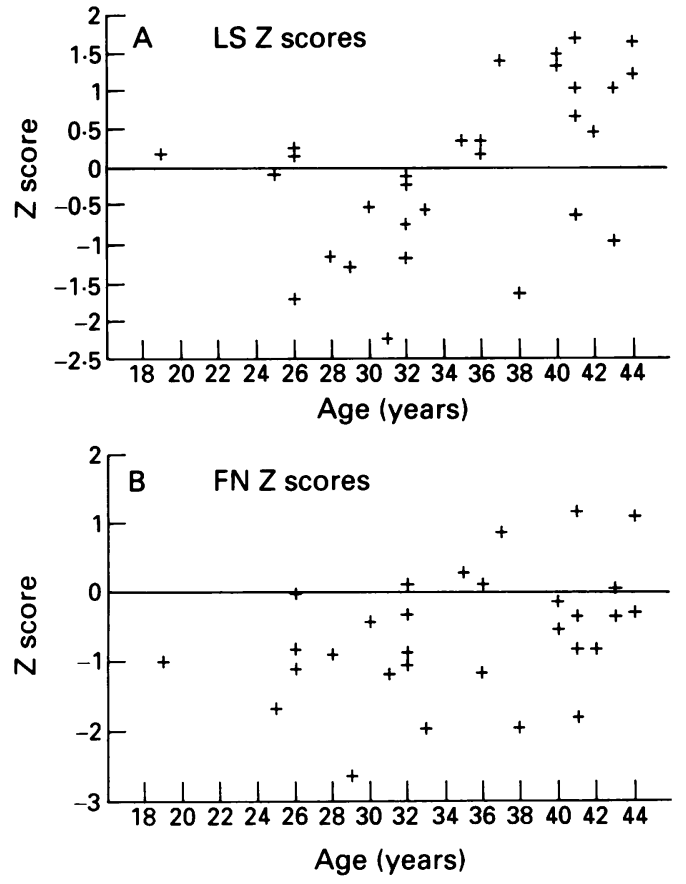

Premenopausal patients with $R A$.

equivalent to a $5 \%$ decrease of absolute BMD values compared to the Hologic reference values. Other studies have shown a significant decrease in LS and FN BMD values in RA patients ${ }^{1-10}$ but have included patients with longstanding disease, greater functional disability with resultant decreased physical activity, and patients taking oral corticosteroids which accelerate bone loss. This study excluded patients taking oral corticosteroids and included patients with a relatively short disease duration (mean duration of two years) to avoid the potential effects of prolonged disability on bone mass.

LS and FN BMD values in the normal population are influenced by age, sex and menopausal status ${ }^{16-17}$ and because of this the cohort was divided into subgroups based on sex and menopausal status for analysis.
Perimenopausal patients were excluded because of the greater variability of bone loss between individuals during this period which may obscure more subtle changes due to the disease process. $Z$ scores are not affected by sex and menopausal status as these reflect the relationship of an individual value with an age and sex matched reference population with the result expressed as a multiple of standard deviation values from the mean with a normal value equal to zero. A mean value which is negative indicates that a group has a lower than predicted mean BMD. The usefulness of $\mathrm{Z}$ scores rely on the Hologic database being comparable with normal individuals from the population being studied. Reference data from France, Belgium and Australia have been shown to closely correlate with North American values within $\pm 2 \%$ over the whole BMD range for spines. ${ }^{18-20}$

Normal premenopausal female $\mathrm{Z}$ scores did not differ significantly from zero in this study indicating that $Z$ scores are a valid reference for this subgroup. Premenopausal female RA patients had significantly reduced FN BMD values particularly affecting the younger patients which was also reflected in the lumbar spine. These findings reflected by the correlation of $\mathrm{Z}$ score changes with age, suggest that the effect of the disease process is more marked before the attainment of peak bone mass during the period of net bone formation. The correlation of body mass with LS and FN $\mathrm{Z}$ scores indicates that premenopausal patients of slighter build are more susceptible to the effects of disease. Age and body mass correlated with each other but were also independent predictors of the femoral neck $Z$ score.

HAQ scores but not the Stoke Index correlated with $\mathrm{FN} \mathrm{Z}$ scores in premenopausal RA patients suggesting that disability, with a concomitant reduction in physical activity, is responsible for the reduction rather than a direct effect of inflammatory mediators related to disease activity. Other studies have also shown an association of FN BMD values with disability $^{6}{ }^{10}$ and physical activity measures. ${ }^{2}$ HAQ score values in the other RA subgroups were comparable but were not associated with FN Z score changes suggesting that mild disability has much less impact on FN BMD in these groups. The lack of association of HAQ scores with LS Z changes either indicates no direct effect of disability on LS BMD or that greater disability is required before there is sufficient change in physical activity to affect the lumbar spine.

No significant association of $\mathrm{Z}$ scores was found with disease duration indicating that there was no large cumulative bone loss occurring in the cohort. Other studies have not found an association but two have indicated that bone loss may be greatest during the first years of disease. ${ }^{6}{ }^{10}$ The lack of association of Stoke Index with $\mathrm{Z}$ score changes indicates that disease activity did not directly affect bone density in this cohort. Both disease activity and $\mathrm{Z}$ score changes, however, were low and the lack of association may reflect the difficulty of comparing on a crossectional basis variables 
which fluctuate daily or weekly with those reflecting cumulative changes over months to years.

In summary, no significant changes of BMD were found in the RA patients except in the femoral neck of premenopausal females which were associated with physical disability, younger age and lower body mass. No relationship of reduction of bone mass with disease activity was found.

Dr A Mahmoud is a Sir Jules Thorn Research Fellow. This work was supported by the Sir Jules Thorne Charitable Trust.

1 Compston J E, Crawley E W, Evans C, et al. Spinal trabecular bone mineral content in patients with nonsteroid treated rheumatoid arthritis. Ann Rheum Dis nonsteroid treated

2 Sambrook P N, Eisman J A, Champion G D, et al. Determinants of axial bone loss in rheumatoid arthritis. Arthritis Rheum 1987; 30: 721-8.

3 Sambrook P N, Eisman J A, Yeates M G, et al. Osteoporosis in rheumatoid arthritis, safety of low dose corticosteroids. Ann Rheum Dis 1986; 45: 950-3.

4 Peretz A, Pract J P, Rozenberg S, et al. Osteocalcin and bone mineral content in rheumatoid arthritis. Clin Rheumatol $1989 ; 8: 42-8$.

5 Reid D M, Kennedy N S J, Smith M A, et al. Total body calcium in rheumatoid arthritis: effects of disease activity calcium in rheumatoid arthritis: effects of disease activity

$6 \mathrm{Als} \mathrm{O}$, Gotfredsen A, Christiansen C. Are disease duration and degree of functional impairment determinants of bone loss in rheumatoid arthritis? Ann Rheum Dis 1985; 44: 406-11

7 O'Malley M, Kenrick A J, Sartoris D J, et al. Axial bone density in rheumatoid arthritis: comparison of dual energy projection radiography and dual photon absorptiometry. Radiology 1989; 170: 501-5.
8 Magaro M, Tricerri A, Piane D, et al. Generalised osteoporosis in nonsteroid treated rheumatoid arthritis. Rheumatology Int 1991; 11: 73-6.

9 Laan R, Van Riel P, Erning L, Lemmens J, Ruijs S, Putte L. Vertebral osteoporosis in rheumatoid arthritis patients: effect of low dose prednisone therapy. $\mathrm{Br} \mathrm{F}$ Rheumatol 1992; 31: 91-6.

10 Laan R, Buijs W, Vobeck A, et al. Bone mineral density in patients with recent onset rheumatoid arthritis: influence of disease activity and functional capacity. Ann Rheum Dis 1993; 52: 21-6.

11 D'Angelo A, Fabris A, Sartovi L, et al. Mineral metabolism and bone mineral content in rheumatoid arthritis. Effect and bone mineral content in rheumatoid arthritis. Effect

12 Arnett F C, Edworthy S M, Bloch D A, et al. The American Rheumatism Association 1987 revised criteria for the classification of rheumatoid arthritis. Arthritis Rheum 1988; 31: 315-24.

13 Ritchie D M, Boyle J A, McInnes J M, et al. Clinical studies with an articular index for the assessment of joint tenderness in patients with rheumatoid arthritis. $Q \mathcal{F} \mathrm{Med}$ 1968; 147: 393-406.

14 Kirwan J R, Reeback J S. Stanford health assessment questionnaire modified to assess disability in British questionnaire modified to assess disability in British patients

15 Davis M J, Dawes P T, Fowler P D, et al. Comparison and evaluation of a disease activity index for use in patients with rheumatoid arthritis. $B r \quad \mathcal{F}$ Rheum 1990; 29: 111-15.

16 Haddaway M J, Davie M W J, McCall I W. Bone mineral density in healthy normal women and reproductability of measurements in spine and hip using dual energy $x$ ray absorptiometry. BrF Radiol 1992; 65: 213-17.

17 Elliott J R, Gilchrist N L, Wells J E, et al. Effects of age and sex on bone density at the hip and spine in a normal sex on bone density at the hip and spine in a normal 33-6.

18 Hall $M$ L, Heavens J, Cullum I D, Ell P J. The range of bone density in normal British women. Br F Radiol 1990; 63: $266-9$.

19 Pocock N A, Eberl S, Mazess R B, et al. Bone mineral density in Australia compared with the United States. f Bone Min Res 1988; 3: 601-4.

20 Hologic QDR-1000 ${ }^{\mathrm{TM}}$. Operators manual and users guide. Hologic Inc, Waltham, MA: Hologic Inc, 1990 